\title{
Associations Between Calcaneal Enthesophytes and Osteoarthritis of the Hands and Feet
}

\begin{tabular}{|c|c|}
\hline Journal: & Arthritis Care and Research \\
\hline Manuscript ID & Draft \\
\hline Wiley - Manuscript type: & Original Article \\
\hline $\begin{array}{r}\text { Date Submitted by the } \\
\text { Author: }\end{array}$ & $\mathrm{n} / \mathrm{a}$ \\
\hline Complete List of Authors: & $\begin{array}{l}\text { Menz, Hylton; La Trobe University, Musculoskeletal Research Centre, } \\
\text { Faculty of Health Sciences } \\
\text { Marshall, Michelle; Keele University, Arthritis Research UK Primary Care } \\
\text { Centre, Primary Care Sciences } \\
\text { Thomas, Martin; Keele University, Arthritis Research UK Primary Care } \\
\text { Centre, Research Institute for Primary Care \& Health Sciences } \\
\text { Rathod, Trishna; Keele University, Research Institute for Primary Care \& } \\
\text { Health Sciences } \\
\text { Peat, George; Keele University, Research Institute for Primary Care \& } \\
\text { Health Sciences } \\
\text { Roddy, Edward; Keele University, Arthritis Research UK Primary Care } \\
\text { Centre }\end{array}$ \\
\hline $\begin{array}{r}\text { Key Words: Please choose } \\
\text { key words for your } \\
\text { manuscript. Choosing the } \\
\text { best match of the journal's } \\
\text { keywords to your work will } \\
\text { likely result in better match to } \\
\text { reviewers with expertise in } \\
\text { your interest area. It may } \\
\text { also help to speed the review } \\
\text { process.: }\end{array}$ & Osteoarthritis, Foot, Hand, Enthesophytes \\
\hline $\begin{array}{r}\text { Optional Terms: You have the } \\
\text { option to add additional key } \\
\text { words that are not on the } \\
\text { journal's list to more } \\
\text { specifically categorize your } \\
\text { submission.: }\end{array}$ & \\
\hline
\end{tabular}




\title{
Associations Between Calcaneal Enthesophytes and Osteoarthritis of the Hands and Feet
}

\author{
Hylton B. Menz, ${ }^{1,2 \bowtie}$ Michelle Marshall, ${ }^{1}$ Martin J. Thomas, ${ }^{1,3}$ Trishna Rathod-Mistry, ${ }^{1}$ \\ George M. Peat ${ }^{1}$, Edward Roddy ${ }^{1,3}$ \\ ${ }^{1}$ Arthritis Research UK Primary Care Centre, Research Institute for Primary Care and Health \\ Sciences, Keele University, Keele, Staffordshire, ST5 5BG, United Kingdom \\ ${ }^{2}$ School of Allied Health, College of Science, Health and Engineering, La Trobe University, \\ Melbourne, Victoria 3086, Australia \\ ${ }^{3}$ Haywood Academic Rheumatology Centre, Midlands Partnership NHS Foundation Trust, \\ Haywood Hospital, Burslem, Staffordshire, ST5 5BG, United Kingdom \\ ${ }^{\bowtie}$ Corresponding author: h.menz@latrobe.edu.au
}

Declaration of interests: none.

\begin{abstract}
Funding: This work was funded by an Arthritis Research UK Programme Grant (18174) and service support through West Midlands North CLRN. HBM is currently a National Health and Medical Research Council of Australia Senior Research Fellow (ID: 1135995). MJT is currently supported by an Integrated Clinical Academic Programme Clinical Lectureship from the National Institute for Health Research (NIHR) and Health Education England (HEE)
\end{abstract} (ICA-CL-2016-02-014). 


\begin{abstract}
Objective. To examine associations between calcaneal enthesophytes and osteoarthritis $(\mathrm{OA})$ in the hands and feet, in order to provide insights into the role of biomechanical and systemic processes in the development of OA.

Methods. Adults aged $\geq 50$ years registered with four general practices were mailed a Health Survey. Responders reporting foot pain within the last 12 months underwent a detailed assessment which included hand and foot radiographs. Calcaneal enthesophytes (plantar and posterior) and OA features (osteophytes and joint space narrowing) were documented. Associations between enthesophytes and hand and foot OA (including OA phenotypes and OA features at individual joints) were explored using generalised estimating equations, adjusting for age, sex and body mass index.
\end{abstract}

Results. Data were available from 532 participants (298 women, mean [SD] age 64.9 [8.4] years). Calcaneal enthesophytes were not associated with hand OA phenotypes or OA at individual hand joints. In contrast, plantar calcaneal enthesophytes were positively associated with polyarticular foot OA (odds ratio [OR] 1.80, 95\% confidence interval [CI] $1.02-3.17)$. When individual foot joints were examined, posterior enthesophytes were associated with talonavicular joint OA (OR 1.58, 95\% CI $1.02-2.44$ ) and plantar enthesophytes were associated with $1^{\text {st }}$ metatarsophalangeal joint OA $(\mathrm{OR} 0.67,95 \% \mathrm{CI}$ $0.49-0.98$ ) and navicular-cuneiform joint OA (OR 2.30, 95\% CI $1.40-3.79$ ). Patterns of association were similar for osteophytes and joint space narrowing.

Conclusion. Calcaneal enthesophytes are more strongly associated with foot OA than hand $\mathrm{OA}$. The pattern of association is suggestive of a local, biomechanical rather than systemic bone-forming process.

Key words: enthesophytes, osteoarthritis, foot, hand 


\section{Significance and Innovations}

- Calcaneal enthesophytes are more strongly associated with foot osteoarthritis (OA) than hand $\mathrm{OA}$

- Patterns of association are similar for osteophytes and joint space narrowing

- These findings suggest that calcaneal enthesophytes represent a local, biomechanical rather than systemic bone-forming process 
Entheses are sites of attachment of tendons, ligaments, fascia or articular capsules to bone (1). When entheses are exposed to metabolic, inflammatory, traumatic or degenerative processes, pathological bone formation may occur, resulting in the development of enthesophytes (bony spurs) (2). Several systemic conditions are associated with enthesophytes, including psoriatic arthritis (3), rheumatoid arthritis (4) and diffuse idiopathic skeletal hyperostosis (5). However, enthesophytes may also develop in response to local mechanical stresses $(6,7)$, and their prevalence, particularly at the foot, increases with age and body mass index (8).

Enthesophytes are also frequently observed in osteoarthritis (OA) (4, 9-11), although their role in the pathophysiology of OA remains uncertain. Examinations of skeletal remains have reported strong associations between generalised enthesophytes and osteophyte formation in the upper and lower limbs $(12,13)$, suggesting that enthesophytes may be indicative of a systemic 'bone-forming' phenotype of OA. This is supported by studies demonstrating strong associations between high bone mass, osteophytes and enthesophytes $(14,15)$. In contrast, only weak associations have been found between hand enthesophytes and hand (16) and knee (17) OA, which suggests that hand enthesophytes may develop in response to local biomechanical factors rather than a systemic bone formation process.

Examining associations between calcaneal enthesophytes and features of OA at local (foot) and remote (hand) sites may provide a useful model for evaluating the relative role of systemic and biomechanical processes in the development of OA. If enthesophytes are indicative of a systemic bone-forming process, one would expect to observe similar associations with $\mathrm{OA}$ at the hand and foot, and stronger associations with osteophytes than joint space narrowing. In contrast, if enthesophytes reflect local mechanical stresses, stronger associations might be observed between calcaneal enthesophytes and foot OA compared to hand OA. Therefore, the objective of this study was to examine the associations between calcaneal enthesophytes (plantar and posterior) and OA features (both osteophytes and joint space narrowing) in joints of the hands and feet. 


\section{MATERIALS AND METHODS}

\section{Study design}

Data were collected via a population-based health survey and research assessment clinic as part of the Clinical Assessment Study of the Foot (18). Adults aged 50 years and over registered with four general practices were invited to take part in the study, irrespective of consultation for foot pain or problems. Ethical approval was obtained from Coventry Research Ethics Committee (reference number: 10/H1210/5).

\section{Data collection}

All eligible participants were mailed a Health Survey questionnaire that gathered information on demographic and social characteristics and general health. Participants who reported pain in and around the foot in the past 12 months and provided written consent to further contact were invited to attend a research clinic where radiographs were obtained from both hands and feet according to standardised protocols $(18,19)$. All films were graded by a single reader (MM) with previously documented intra-rater reliability $(20,21)$. For the hands, dorso-palmar views were obtained (20), and graded for the presence and severity of OA using the Kellgren and Lawrence (K\&L) grading system. Standardised scoring was completed for 11 joints in each hand and wrist: the distal interphalangeal (DIP), proximal interphalangeal (PIP), the thumb interphalangeal (IP), the first carpometacarpal (CMC) and the trapezioscaphoid (TS) joints. Radiographic OA for an individual hand joint was defined as the presence of $K \& L \geq 2$. Three hand OA phenotypes were documented as described previously: generalised hand OA (defined as K\&L $\geq 2$ in $\geq 1$ DIPJ and $\geq 1$ PIPJ and $\geq 1$ first CMCJ across either hand), thumb base OA (defined as $K \& \mathrm{~L} \geq 2$ in first CMCJ in either hand), and IPJ OA (defined as K\&L $\geq 2$ in $\geq 2$ IPJ [rays 2-5] across either hand) (22).

For the feet, weightbearing dorso-plantar and lateral views were obtained, and osteophytes and joint space narrowing at the first metatarsophalangeal (MTP), first and second cuneometatarsal (CM), navicular-cuneiform (NC) and talo-navicular (TN) joints were graded (0-3) according to a validated atlas (23). Radiographic OA at each individual joint was defined as a score of 2 or more for osteophytes or joint space narrowing on either dorso-plantar or lateral views, and two foot OA phenotypes (first MTP OA and polyarticular 
foot OA) were documented as previously described (24). Plantar and posterior calcaneal enthesophytes were documented from lateral x-rays as absent (score $=0)$, small ( score $=1$ ), moderate $($ score $=2$ ) or severe ( score $=3$ ) using standard atlas images (Figure 1), and then dichotomised as possible ( $\operatorname{score}=0$ or 1 ) or definite ( reliability of enthesophyte scoring, HBM and MM independently scored 120 lateral radiographs (60 right foot, 60 left foot). Reliability was excellent for both plantar and posterior enthesophytes (quadratic weighted kappa 0.82, 95\% CI $0.76-0.89$; percentage agreement $94 \%$ and $0.79,95 \%$ CI $0.70-0.88 ; 94 \%$, respectively).

\section{Statistical analysis}

All analyses were conducted using SPSS Version 22 (IBM Corporation, Armonk, NY). Person-level associations between enthesophytes and hand and foot OA phenotypes were explored using logistic regression. Individual joint associations between enthesophytes and OA features (OA case definition, osteophytes and joint space narrowing) in each hand and foot joint were explored using generalised estimating equations to account for the correlation between measurements obtained from the right and left limbs in the participant. Age, sex and body mass index were considered to be confounding variables and were adjusted for in all analyses. Odds ratios with $95 \%$ confidence intervals are presented and statistical significance was determined as $p<0.05$.

\section{RESULTS}

\section{Study population}

As previously reported, a total of 5,109 completed Health Survey questionnaires were received (adjusted response 56\%) (21). Of these, 1,635 individuals who reported pain in and around the foot in the past 12 months and provided written consent to further contact were invited to the research assessment clinic and 560 attended. Individuals with inflammatory arthritis ( $n=24)$ were excluded, and complete hand and foot radiographs were unavailable for 4 participants, leaving a total of 532 eligible participants for this analysis (298 women and 234 men, mean [SD] age 64.9 [8.4] years, mean [SD] body mass index 30.4 [5.6] $\left.\mathrm{kg} / \mathrm{m}^{2}\right)$. 


\section{Prevalence of enthesophytes and OA features}

Posterior enthesophytes were present in 174 feet (16\%) and plantar enthesophytes were present in 283 feet (27\%). The prevalence of hand OA phenotypes was as follows: no hand OA ( $n=250$ participants, 47\%), generalised hand OA $(n=46,9 \%)$, thumb base OA $(n=227$, $43 \%)$ and IPJ OA ( $n=137,26 \%)$. The prevalence of foot OA phenotypes was as follows: no or minimal foot OA ( $\mathrm{n}=340$ participants, $64 \%)$, isolated $1^{\text {st }}$ MTPJ OA $(n=115,22 \%)$ and polyarticular foot OA $(\mathrm{n}=77,14 \%)$.

\section{Associations between calcaneal enthesophytes and hand and foot $\mathrm{OA}$ phenotypes}

Table 1 reports the person-level associations between calcaneal enthesophytes and foot and hand OA phenotypes. Odds ratios (ORs) ranged from 0.69 to 1.80. There was a reduced odds of having a plantar enthesophyte in those with thumb base OA (OR 0.69, 95\% confidence interval [CI] $0.46-1.03$, although not reaching statistical significance), and an increased odds of having a plantar enthesophyte in those with polyarticular foot OA (OR $1.80,95 \%$ CI $1.02-3.17, p<0.05)$.

\section{Associations between calcaneal enthesophytes and hand OA}

Table 2 reports individual joint associations between calcaneal enthesophytes and hand OA. ORs ranged from 0.25 to 1.70 , but the confidence intervals were wide. There were no significant associations between enthesophytes and hand OA features, with the exception of plantar enthesophytes being negatively associated with joint space narrowing of the middle finger DIPJ (OR 0.25, 95\% CI $0.10-0.65, p<0.05$ ).

\section{Associations between calcaneal enthesophytes and foot $\mathrm{OA}$}

Table 3 reports individual joint associations between calcaneal enthesophytes and foot OA. ORs ranged from 0.41 to 3.12. Posterior enthesophytes were significantly associated with OA of the TNJ (OR 1.58, 95\% CI $1.02-2.44, p<0.05$ ) and osteophytes of the TNJ (OR $1.63,95 \%$ CI $1.03-2.58, p<0.05)$, while plantar enthesophytes were significantly associated with OA of the $1^{\text {st }}$ MTPJ (OR 0.67, 95\% CI $\left.0.48-0.94, p<0.05\right)$ and NCJ (OR 2.30, 95\% CI $1.40-3.79, p<0.01$ ), osteophytes of the $1^{\text {st }}$ MTPJ (OR $0.69,95 \%$ CI $0.49-0.98, p<0.05$ ) 
and NCJ (OR 3.12, 95\%CI $1.67-5.85, p<001)$, and joint space narrowing of the NCJ (OR $2.56,95 \%$ CI $1.39-4.74, p<0.01)$.

\section{DISCUSSION}

The objective of this study was to examine associations between calcaneal enthesophytes and osteoarthritis (OA) in the hands and feet, in order to provide insights into the role of biomechanical and systemic processes in the development of OA. We found that calcaneal enthesophytes were not associated with any hand OA phenotype or with the case definition of $\mathrm{OA}$ at individual hand joints. In contrast, plantar calcaneal enthesophytes were associated with the polyarticular foot OA phenotype and with OA features at several individual foot joints. Taken together, these findings suggest that calcaneal enthesophytes may result from a local, biomechanical process rather than a systemic 'bone forming' process.

Our findings are inconsistent with those of Rogers et al $(12,13)$, who reported strong associations between generalised enthesophytes and osteophytes in the upper and lower limbs in skeletal remains. However, it has been argued that differentiating between osteophytes and enthesophytes may be difficult in such specimens, and the inability to accurately determine the age of the specimens may have led to confounding (25). Indeed, subsequent studies that adjusted for age reported no association between hand enthesophytes and bone marrow lesions at the knee (17), no or weak associations between enthesophytes and osteophytes in the hand $(16,26)$, and no association between calcaneal enthesophytes and upper or lower limb OA (11). Our findings are similar and suggest that although enthesophytes and osteophytes frequently coexist, they may be initiated by different processes.

Osteophytes develop through a process of chondrocyte hypertrophy and endochondral ossification, resulting in deposition of bone in the periosteum. Although this pathway is thought to be initiated by both mechanical and biochemical stimuli, observations of cartilage formation in the periosteum of immobilised joints suggest that mechanical stresses are not essential for osteophyte development (27). Enthesophytes also develop in response to endochondral ossification and may therefore have a similar pathophysiology to osteophytes. However, calcaneal enthesophytes in particular may be more responsive to mechanical stimuli due to the weightbearing function of the foot. Indeed, histological studies suggest that calcaneal enthesophytes increase the surface area of the interface between tendon and 
bone, and may therefore be an adaptive mechanism to protect the enthesis from excessive mechanical loading $(6,28)$.

We found several associations between calcaneal enthesophytes and OA features in foot joints that may be indicative of a local, mechanical aetiology. First, posterior calcaneal enthesophytes, which are thought to result from increased tensile forces in the Achilles tendon (28), were positively associated with talonavicular joint OA. The talonavicular joint is a ball and socket joint that moves in concert with the subtalar/ankle joint complex and has a significant dorsiflexion component (29). In the presence of OA, it is likely that the available range of dorsiflexion at the talonavicular joint is decreased, thereby leading to greater tension in the Achilles tendon as the tibia moves over the foot during the propulsive phase of gait. Second, plantar enthesophytes were positively associated with the polyarticular foot OA phenotype and OA affecting the navicular-cuneiform joint. OA affecting the midfoot joints has been associated with pronated ('flat') foot type $(30,31)$, which is in turn associated with increased traction of the insertion of the plantar fascia into the calcaneal enthesis (32). Finally, the negative association between plantar enthesophytes and $1^{\text {st }}$ MTPJ OA may also be related to the role of foot posture, as while plantar enthesophytes are positively associated with pronated foot posture $(33,34), 1^{\text {st }}$ MTPJ OA is $\operatorname{not}(35)$.

Strengths of our study include the population-based sample and the use of standardised imaging and assessment for both the hands and feet. However, our findings need to be interpreted in the context of several limitations. First, the overall response to the postal health survey questionnaire from which the clinical sample was derived was lower than expected. However, responders to the questionnaire did not differ greatly from the mailed population (21). Second, we did not have access to knee radiographs in this population, which would have enabled more direct comparisons to previous studies $(14,15,17)$ and provided an additional remote site to examine these associations. Third, our use of radiographs did not enable us to identify the precise location of the calcaneal enthesophytes. Although posterior enthesophytes are most commonly located within the Achilles tendon, plantar enthesophytes are more variable, and may develop within intrinsic muscles and loose connective tissue as well as within the plantar fascia itself (36). Finally, our interpretation of the possible mechanical links between enthesophytes and OA in the foot is inherently speculative and requires confirmation with biomechanical assessment techniques. 
In summary, our study has shown that calcaneal enthesophytes are more strongly associated with foot OA than hand OA and have similar associations with osteophytes and joint space narrowing. This pattern of association suggests that calcaneal enthesophytes primarily result from a local, biomechanical process rather than a systemic 'bone forming' process. Future investigations incorporating observations of osteophytes and enthesophytes from multiple joints are required to provide further insights into the relative role of systemic and biomechanical processes in the pathophysiology of OA. 


\section{AUTHOR CONTRIBUTIONS}

All authors were involved in drafting the article or revising it critically for important intellectual content, and all authors approved the final version to be submitted for publication. Dr. Menz had full access to all of the data in the study and takes responsibility for the integrity of the data and the accuracy of the data analysis.

Study conception and design. Menz, Marshall, Thomas, Peat, Roddy.

Acquisition of data. Marshall, Thomas, Roddy.

Analysis and interpretation of data. Menz, Marshall, Thomas, Rathod-Mistry, Peat, Roddy

\section{ACKNOWLEDGEMENTS}

We would like to thank the administrative, health informatics and research nurse teams of Keele University's Arthritis Research UK Primary Care Centre, the staff of the participating general practices and the Haywood Hospital, particularly Dr Jackie Saklatvala, Carole Jackson and the radiographers at the Department of Radiology. We would like to acknowledge the contributions of Linda Hargreaves, Gillian Levey, Liz Mason, Dr Jennifer Pearson, Julie Taylor and Dr Laurence Wood to data collection. 


\section{REFERENCES}

1. Slobodin G, Rozenbaum M, Boulman N, Rosner I. Varied presentations of enthesopathy. Semin Arthritis Rheum. 2007;37(2):119-26.

2. Schett G, Lories RJ, D'Agostino MA, Elewaut D, Kirkham B, Soriano ER, et al. Enthesitis: from pathophysiology to treatment. Nat Rev Rheumatol. 2017;13(12):731-41.

3. Gladman DD, Abufayyah M, Salonen D, Thavaneswaran A, Chandran V. Radiological characteristics of the calcaneal spurs in psoriatic arthritis. Clin Exp Rheumatol.

2014;32(3):401-3.

4. Gerster JC, Vischer TL, Bennani A, Fallet GH. The painful heel. Comparative study in rheumatoid arthritis, ankylosing spondylitis, Reiter's syndrome, and generalized osteoarthrosis. Ann Rheum Dis. 1977;36:343-8.

5. Resnick D, Niwayama G. Radiographic and pathologic features of spinal involvement in diffuse idiopathic skeletal hyperostosis (DISH). Radiology. 1976;119(3):559-68.

6. Kumai T, Benjamin M. Heel spur formation and the subcalcaneal enthesis of the plantar fascia. J Rheumatol. 2002;29:1957-64.

7. Radin E, Parker H, Paul I. Pattern of degenerative arthritis: preferential involvement of distal finger-joints. Lancet. 1971;297(7695):377-9.

8. Kirkpatrick J, Yassaie O, Mirjalili SA. The plantar calcaneal spur: a review of anatomy, histology, etiology and key associations. J Anat. 2017;230(6):743-51.

9. Bassiouni M. Incidence of calcaneal spurs in osteo-arthrosis and rheumatoid arthritis, and in control patients. Ann Rheum Dis. 1965;24:490-3.

10. Menz HB, Zammit GV, Landorf KB, Munteanu SE. Plantar calcaneal spurs in older people: longitudinal traction or vertical compression? J Foot Ankle Res. 2008;1(1):7.

11. Weiss E. Calcaneal spurs: Examining etiology using prehistoric skeletal remains to understand present day heel pain. Foot. 2012;22(3):125-9.

12. Rogers J, Shepstone L, Dieppe P. Bone formers: osteophyte and enthesophyte formation are positively associated. Ann Rheum Dis. 1997;56(2):85-90.

13. Rogers J, Shepstone L, Dieppe P. Is osteoarthritis a systemic disorder of bone? Arthritis Rheum. 2004;50(2):452-7.

14. Hardcastle SA, Dieppe P, Gregson CL, Arden NK, Spector TD, Hart DJ, et al. Osteophytes, enthesophytes, and high bone mass: a bone-forming triad with potential relevance in osteoarthritis. Arthritis Rheum. 2014;66(9):2429-39. 
15. Gregson CL, Hardcastle SA, Murphy A, Faber B, Fraser WD, Williams M, et al. High Bone Mass is associated with bone-forming features of osteoarthritis in non-weight bearing joints independent of body mass index. Bone. 2017;97:306-13.

16. Karasik D, Kiel DP, Kiely DK, Cupples LA, Wilson PW, O'Donnell CJ, et al. Abdominal aortic calcification and exostoses at the hand and lumbar spine: the Framingham Study. Calcif Tissue Int. 2006;78(1):1-8.

17. Gibson N, Guermazi A, Clancy M, Niu J, Grayson P, Aliabadi P, et al. Relation of hand enthesophytes with knee enthesopathy: is osteoarthritis related to a systemic enthesopathy? J Rheumatol. 2012;39(2):359-64.

18. Roddy E, Myers H, Thomas MJ, Marshall M, D'Cruz D, Menz HB, et al. The clinical assessment study of the foot (CASF): study procotol for a prospective observational study of foot pain and foot osteoarthritis in the general population. J Foot Ankle Res. 2011;4:22.

19. Myers H, Nicholls E, Handy J, Peat G, Thomas E, Duncan R, et al. The Clinical Assessment Study of the Hand (CAS-HA): a prospective study of musculoskeletal hand problems in the general population. BMC Musculoskelet Disord. 2007;8:85.

20. Marshall M, van der Windt D, Nicholls E, Myers H, Hay E, Dziedzic K. Radiographic hand osteoarthritis: patterns and associations with hand pain and function in a communitydwelling sample. Osteoarthritis Cartilage. 2009;17(11):1440-7.

21. Roddy E, Thomas MJ, Marshall M, Rathod T, Myers H, Menz HB, et al. The population prevalence of symptomatic radiographic foot osteoarthritis in community-dwelling older adults: the Clinical Assessment Study of the Foot. Ann Rheum Dis. 2015;74:156-63.

22. Marshall M, Peat G, Nicholls E, van der Windt D, Myers H, Dziedzic K. Subsets of symptomatic hand osteoarthritis in community-dwelling older adults in the United Kingdom: prevalence, inter-relationships, risk factor profiles and clinical characteristics at baseline and 3-years. Osteoarthritis Cartilage. 2013;21(11):1674-84.

23. Menz HB, Munteanu SE, Landorf KB, Zammit GV, Cicuttini FM. Radiographic classification of osteoarthritis in commonly affected joints of the foot. Osteoarthritis Cartilage. 2007; 15:1333-8.

24. Rathod T, Marshall M, Thomas MJ, Menz HB, Myers HL, Thomas E, et al. Investigations of Potential Phenotypes of Foot Osteoarthritis: Cross-Sectional Analysis From the Clinical Assessment Study of the Foot. Arthritis Care Res. 2016;68(2):217-27.

25. Felson DT, Neogi T. Osteoarthritis: is it a disease of cartilage or of bone? Arthritis Rheum. 2004;50(2):341-4.

26. Kalichman L, Malkin I, Kobyliansky E. Hand bone midshaft enthesophytes: the influence of age, sex, and heritability. Osteoarthritis Cartilage. 2007;15(10):1113-9.

27. van der Kraan PM, van den Berg WB. Osteophytes: relevance and biology. Osteoarthritis Cartilage. 2007;15(3):237-44. 
28. Benjamin M, Rufai A, Ralphs JR. The mechanism of formation of bony spurs (enthesophytes) in the achilles tendon. Arthritis Rheum. 2000;43(3):576-83.

29. Lundgren P, Nester C, Liu A, Arndt A, Jones R, Stacoff A, et al. Invasive in vivo measurement of rear-, mid- and forefoot motion during walking. Gait Posture. 2008;28(1):93-100.

30. Menz HB, Munteanu SE, Zammit GV, Landorf KB. Foot structure and function in older people with radiographic osteoarthritis of the medial midfoot. Osteoarthritis Cartilage. 2010;18(3):317-22.

31. Thomas MJ, Roddy E, Rathod T, Marshall M, Moore A, Menz HB, et al. Clinical diagnosis of symptomatic midfoot osteoarthritis: cross-sectional findings from the Clinical Assessment Study of the Foot. Osteoarthritis Cartilage. 2015;23(12):2094-101.

32. Kim W, Voloshin AS. Role of plantar fascia in the load bearing capacity of the human foot. J Biomech. 1995;28(9):1025-33.

33. Shama SS, Kominsky SJ, Lemont H. Prevalence of non-painful heel spur and its relation to postural foot position. J Am Podiatr Assoc. 1983;73:122-3.

34. Prichasuk S, Subhadrabandhu T. The relationship of pes planus and calcaneal spur to plantar heel pain. Clin Orthop Relat Res. 1994;306:192-6.

35. Zammit GV, Menz HB, Munteanu SE. Structural factors associated with hallux limitus/rigidus: a systematic review of case control studies. J Orthop Sports Phys Ther 2009;39(10):733-42.

36. Li J, Muehleman C. Anatomic relationship of heel spur to surrounding soft tissues: greater variability than previously reported. Clin Anat. 2007;20(8):950-5. 


\section{Figure legends}

Figure 1. Standardised images used to identify presence of posterior and plantar calcaneal enthesophytes. Enthesophytes were considered to be definitely present if a score of 2 or above was documented. 
Posterior calcaneal enthesophytes

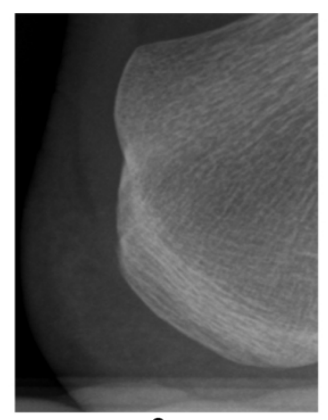

0

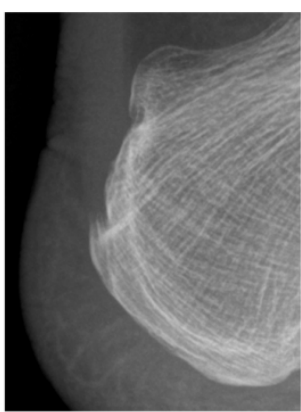

1

Plantar calcaneal enthesophytes
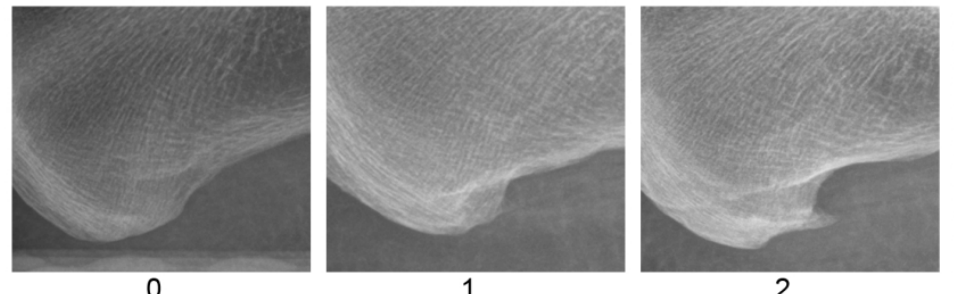

2

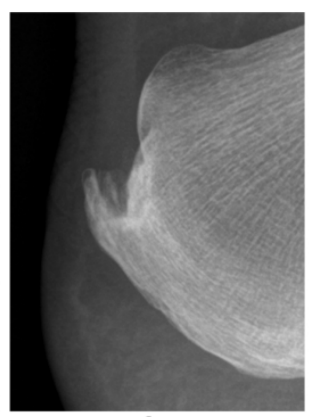

3

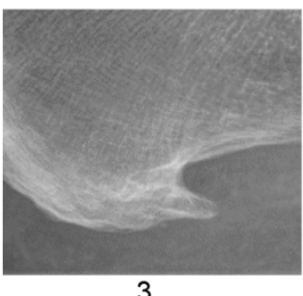

Figure 1. Standardised images used to identify presence of posterior and plantar calcaneal enthesophytes. Enthesophytes were considered to be definitely present if a score of 2 or above was documented. 
Table 1. Associations between hand OA phenotypes, foot OA phenotypes and enthesophytes. ${ }^{1}$ Data are odds ratios $(95 \%$ confidence intervals).

\begin{tabular}{|c|c|c|}
\hline & Posterior enthesophyte & Plantar enthesophyte \\
\hline \multicolumn{3}{|l|}{ Hand $\mathrm{OA}^{2}$} \\
\hline Generalised & $0.75(0.33-1.71)$ & $0.93(0.45-1.91)$ \\
\hline Thumb base & $1.06(0.70-1.62)$ & $0.69(0.46-1.03)$ \\
\hline IPJ & $1.16(0.72-1.89)$ & $1.02(0.65-1.61)$ \\
\hline \multicolumn{3}{|l|}{ Foot $\mathrm{OA}^{3}$} \\
\hline $1^{\text {st }}$ MTPJ & $1.08(0.65-1.78)$ & $0.93(0.58-1.50)$ \\
\hline Polyarticular & $1.30(0.71-2.36)$ & $1.80(1.02-3.17)^{*}$ \\
\hline $\begin{array}{l}\text { Notes: } \\
1 \text { analysis at person level, lo } \\
2 \text { overlapping hand OA phen } \\
3 \text { discrete foot OA phenotyp } \\
* p<0.05\end{array}$ & $\begin{array}{l}\text { ted for age, sex and body } n \\
\text { let al (22). Reference categ } \\
\text { 24). Reference category is }\end{array}$ & $\begin{array}{l}\text { OA or other two phenotype } \\
\text { oot OA }\end{array}$ \\
\hline
\end{tabular}


Table 2. Associations between enthesophytes and OA in each hand joint. ${ }^{1}$ Data are odds ratios (95\% confidence intervals).

\begin{tabular}{lcccccc} 
& \multicolumn{3}{c}{ Posterior enthesophytes } & \multicolumn{3}{c}{ Plantar enthesophytes } \\
\cline { 2 - 7 } & $\mathrm{OA}^{2}$ & $\mathrm{OP}^{2}$ & $\mathrm{JSN}^{2}$ & $\mathrm{OA}^{2}$ & $\mathrm{OP}^{2}$ & JSN $^{2}$ \\
\hline Little finger DIPJ & $1.10(0.68-1.78)$ & $0.86(0.29-2.54)$ & $0.74(0.34-1.62)$ & $0.81(0.55-1.20)$ & $0.62(0.34-1.14)$ & $0.88(0.49-1.60)$ \\
Ring finger DIPJ & $1.05(0.51-2.14)$ & $1.61(0.66-3.93)$ & $0.83(0.33-2.09)$ & $0.89(0.49-1.61)$ & $0.85(0.33-2.18)$ & $0.49(0.21-1.14)$ \\
Middle finger DIPJ & $0.92(0.53-1.63)$ & $0.92(0.46-1.84)$ & $0.42(0.17-1.03)$ & $0.76(0.46-1.25)$ & $0.71(0.40-1.28)$ & $0.25(0.10-0.65)^{*}$ \\
Index finger DIPJ & $0.88(0.55-1.39)$ & $0.90(0.51-1.56)$ & $0.72(0.36-1.43)$ & $1.12(0.77-1.63)$ & $0.93(0.50-1.73)$ & $0.82(0.40-1.66)$ \\
Little finger PIPJ & $0.99(0.47-2.09)$ & $0.73(0.12-4.38)$ & $0.62(0.07-5.43)$ & $1.35(0.72-2.54)$ & $0.58(0.09-3.55)$ & $0.44(0.05-3.88)$ \\
Ring finger PIPJ & $0.28(0.04-1.96)$ & $\mathrm{NC}$ & $0.51(0.05-5.72)$ & $0.35(0.10-1.13)$ & $0.27(0.03-2.54)$ & $1.02(0.40-2.58)$ \\
Middle finger PIPJ & $0.88(0.40-1.95)$ & $\mathrm{NC}$ & $0.70(0.15-3.23)$ & $0.81(0.40-1.65)$ & $\mathrm{NC}$ & $0.96(0.31-3.03)$ \\
Index finger PIPJ & $0.71(0.35-1.43)$ & $1.70(0.55-5.24)$ & $0.70(0.15-3.23)$ & $1.19(0.68-2.09)$ & $0.78(0.24-2.52)$ & $0.96(0.31-3.03)$ \\
Thumb IPJ & $1.05(0.68-1.63)$ & $\mathrm{NC}$ & $\mathrm{NC}$ & $0.81(0.54-1.23)$ & $\mathrm{NC}$ & $\mathrm{NC}$ \\
CMCJ & $0.92(0.61-1.40)$ & $0.96(0.55-1.67)$ & $0.70(0.32-1.57)$ & $0.88(0.64-1.21)$ & $1.20(0.79-1.84)$ & $0.63(0.33-1.21)$ \\
TSJ & $1.02(0.51-2.03)$ & $\mathrm{NC}$ & $\mathrm{NC}$ & $1.07(0.61-1.88)$ & $\mathrm{NC}$ & $\mathrm{NC}$ \\
\hline
\end{tabular}

Notes:

1 analysis at the hand level, generalised estimating equations adjusted for age, sex and body mass index

${ }^{2}$ osteoarthritis (OA), osteophyte (OP) and joint space narrowing (JSN) according to Kellgren and Lawrence score $\geq 2$

$* p<0.05$

NC: not calculable due to insufficient cell count 
Table 3. Associations between enthesophytes and OA in each foot joint. ${ }^{1}$ Data are odds ratios ( $95 \%$ confidence intervals).

\begin{tabular}{lcccccc} 
& \multicolumn{3}{c}{ Posterior enthesophytes } & \multicolumn{3}{c}{ Plantar enthesophytes } \\
\cline { 2 - 7 } & $\mathrm{OA}^{2}$ & $\mathrm{OP}^{3}$ & $\mathrm{JSN}^{4}$ & $\mathrm{OA}^{2}$ & $\mathrm{OP}^{3}$ & JSN $^{4}$ \\
\hline $1^{\text {st }}$ MTPJ & $0.75(0.51-1.11)$ & $0.73(0.49-1.07)$ & $0.86(0.50-1.48)$ & $0.67(0.48-0.94)^{*}$ & $0.69(0.49-0.98)^{*}$ & $1.02(0.61-1.69)$ \\
$1^{\text {st }} \mathrm{CMJ}$ & $0.70(0.31-1.59)$ & $0.84(0.34-2.05)$ & $0.41(0.09-1.83)$ & $1.28(0.71-2.31)$ & $1.17(0.52-2.64)$ & $1.33(0.61-2.94)$ \\
$2^{\text {nd }} \mathrm{CMJ}$ & $1.03(0.64-1.65)$ & $1.14(0.60-2.17)$ & $0.92(0.54-1.58)$ & $1.41(0.95-2.09)$ & $1.26(0.72-2.22)$ & $1.44(0.93-2.21)$ \\
$\mathrm{NCJ}$ & $1.09(0.56-2.12)$ & $1.49(0.74-3.00)$ & $0.76(0.32-1.83)$ & $2.30(1.40-3.79)^{* *}$ & $3.12(1.67-5.85)^{* *}$ & $2.56(1.39-4.74)^{* *}$ \\
TNJ & $1.58(1.02-2.44)^{*}$ & $1.63(1.03-2.58)^{*}$ & $1.33(0.54-3.27)$ & $1.15(0.78-1.70)$ & $1.15(0.76-1.73)$ & $1.27(0.70-2.32)$ \\
\hline
\end{tabular}

Notes:

${ }^{1}$ analysis at the foot level, generalised estimating equations adjusted for age, sex and body mass index

${ }^{2}$ osteoarthritis case definition using Menz et al (23) atlas

${ }^{3}$ osteophyte score of $\geq 2$ using Menz et al (23) atlas

4 joint space narrowing score of $\geq 2$ using Menz et al (23) atlas

$* p<0.05, * * p<0.01$ 